\title{
Green photochemistry: Production of fine chemicals with sunlight*
}

\author{
Michael Oelgemöller ${ }^{1, \ddagger}$, Christian Jung ${ }^{2}$, and Jochen Mattay ${ }^{3}$ \\ ${ }^{1}$ School of Chemical Sciences and National Institute for Cellular Biotechnology, \\ Dublin City University, Dublin 9, Ireland; ${ }^{2}$ German Aerospace Center (DLR), \\ Solarforschung, Linder Höhe, D-51147 Cologne, Germany; ${ }^{3}$ Organic Chemistry I, \\ Department of Chemistry, University of Bielefeld, P.O. Box 1001 31, D-33501 \\ Bielefeld, Germany
}

\begin{abstract}
Three photochemical reactions were investigated under solar irradiation conditions with moderately concentrated sunlight: the photoacylation of naphthoquinone with butyraldehyde and the dye-sensitized photooxygenations of citronellol and 1,5-dihydroxynaphthalene, respectively. All reactions were easily performed on multigram-to-kilogram scales using cheap and commercially available starting materials, and yielded important key intermediates for industrial applications.
\end{abstract}

Keywords: solar chemistry; photoacylation; photooxygenation; green chemistry; photochemistry.

\section{INTRODUCTION}

Over the last few decades, the call for sustainable and environmentally friendly technologies has led to an increasing interest in green chemistry [1]. Among the known green chemical approaches, organic photochemistry can serve as a valuable application since light is regarded as a clean and traceless reagent [2]. Despite this advantage, however, synthetic organic photochemistry has been widely ignored by the chemical industry. The main reason for this neglect is the high energy demand of most artificial light sources. Scharf and coworkers have recently used concentrated sunlight as an alternative and "freely available" light source for the solar chemical production of selected fine chemicals [3]. This concept leads back to the beginnings of organic photochemistry in the late $19^{\text {th }}$ century when sunlight was the only available source of radiation [4]. In contrast to the often improvised early equipment, today's solar photochemical reactions are performed with modern solar reactors and moderately to highly concentrated sunlight which allow high time-space yields [5]. During the last decade, we have realized a number of solar syntheses, and representative examples will be highlighted in this article [6]. Full experimental results and discussions can be found in the original articles.

\section{RESULTS AND DISCUSSION}

Close to Cologne, Germany, the German Aerospace Center (DLR) operates a solar chemical research facility (Fig. 1a). Each year, the site of DLR (latitude 50 $51^{\prime} \mathrm{N}, 7^{\circ} 07^{\prime} \mathrm{E}, 70 \mathrm{~m}$ above sea level) receives about $1500 \mathrm{~h}$ of direct sunshine (with a peak in July/August) and about $850 \mathrm{kWh} / \mathrm{m}^{2}$ of direct insola-

*Pure Appl. Chem. 79, 1831-2100. An issue of reviews and research papers based on lectures presented at the $1^{\text {st }}$ International IUPAC Conference on Green-Sustainable Chemistry, held in Dresden, Germany, 10-15 September 2006.

¥Corresponding author: Tel.: +353-1-700-5312; Fax: +353-1-700-5503; E-mail: michael.oelgemoeller@dcu.ie 

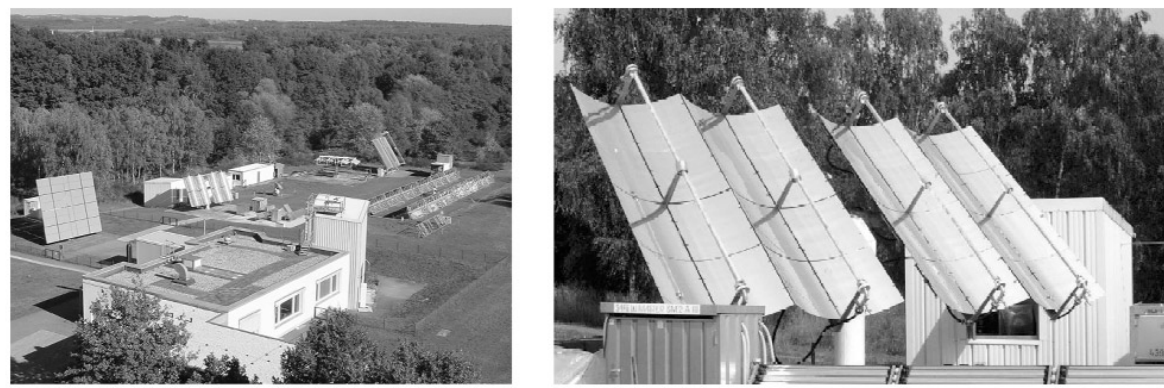

Fig. 1 (a) Solar chemical research plant at DLR in Cologne, Germany; (b) PROPHIS-loop.

tion, which makes it a suitable location for solar chemical operations. The research plant comprises a high-flux solar furnace and several other sunlight-collecting systems [7]. With the exception of the photooxygenation of 1,5-dihydroxynaphthalene (vide infra), the Parabolic Trough Facility for Organic Photochemical Synthesis (PROPHIS) reactor was used as a sunlight-collecting system [8]. The loop (Fig. 1b) is based on a line-focusing parabolic trough collector and comprises a MAN-Helioman module (four troughs) and feeding equipment (storage vessel, pump, heat exchanger, gas fitting, etc.), the latter placed nearby in a separated shed. This reactor type requires direct sunlight since it can only concentrate the direct part of the global radiation. The collector enables a geometric concentration factor corresponding to about 32 suns, but its efficiency is reduced in practice due to optical losses. The mirror elements (each $1 \mathrm{~m}^{2} ; 8$ elements per trough) are made of silver-coated glass and follow the sun by a three-dimensional tracking system on two axes. The given storage vessel and feeding equipment allow experiments on 35 to 1201 scales.

While passing through the atmosphere, the solar photon stream is changed in intensity and spectral distribution. Furthermore, the quality of the direct sunlight that reaches the earth's surface is strongly dependent on the geographic location. For Cologne, Germany, Fig. 2 shows the calculated molar spectral direct solar irradiance $\left(E_{p \lambda}\right)$ on 10 October 1995 (12:00 a.m.) together with the extraterrestrial irradiance [9]. It is important to note that not all organic photoreactions known from the laboratory are suitable for solar chemical applications. For example, no solar photons in the photochemically important region below $300 \mathrm{~nm}$ are detectable on the earth's surface. Additionally, only the region up to the threshold wavelength $\left(\lambda_{\mathrm{s}}\right)$ of $700 \mathrm{~nm}$ is energetically suitable to induce structural changes. For our studies, we have selected photoacylations involving quinones and dye-sensitized photooxygenations. Both types of reactions match nicely with the solar spectrum (see insets in Fig. 2).

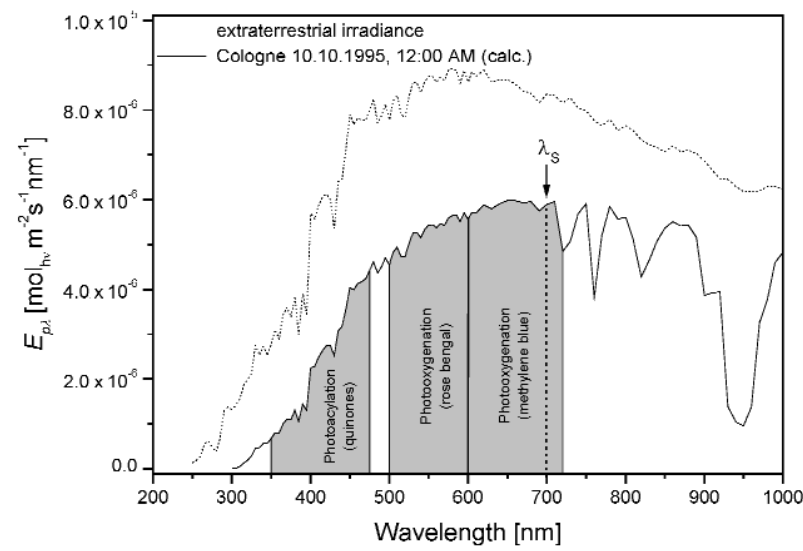

Fig. 2 Extraterrestrial irradiance and calculated molar spectral direct solar irradiance for Cologne, Germany. 


\section{Photoacylation of quinones}

Due to their absorption at wavelengths above $350 \mathrm{~nm}$, quinones are excellent substrates for solar chemical applications. Thus, we have chosen the photochemical reaction between a quinone and an aldehyde as a mild and efficient alternative to thermal Friedel-Crafts acylations or Fries rearrangements [10]. This photoacylation was discovered in 1891 by Heinrich Klinger who exposed the starting materials to natural sunlight over long periods of time [11]. To find optimal reaction conditions for our modern "outdoor" approach, we studied the photoacylation in detail with artificial light [12]. A major disadvantage of the laboratory protocol was the usage of the toxic solvents benzene or acetonitrile, but nontoxic tertiary butanol was found to be a suitable alternative. For our model reaction between 1,4-naphthoquinone (1) and butyraldehyde (2), the photoproduct (3) was obtained in an isolated yield of $84 \%$. With these optimized reaction conditions, the photoacylation of the 1/2-pair (Scheme 1) was performed on a $500 \mathrm{~g}$ $(3.2 \mathrm{~mol}, 1)$ scale using the PROPHIS plant (three troughs $\left.=24 \mathrm{~m}^{2}\right)$ [13]. Due to the difficulty of handling pure tertiary butanol (relatively low melting point), a 3:1 mixture with acetone was used instead.<smiles>O=CC(=O)c1ccccc1C=O</smiles>

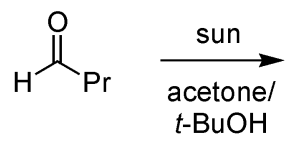<smiles>CCCC(=O)c1cc(O)c2ccccc2c1O</smiles>

Scheme 1 Photoacylation of 1,4-naphthoquinone with butyraldehyde.

The illumination took place during 20 and 22 August 1996 for a total illumination time of $24 \mathrm{~h}$ (CEST: 09:00-17:00 each day). As is not untypical for the location and time of the year, the weather conditions were varying, and only the first day was optimal for reaching a high conversion. This becomes apparent when comparing the direct normal irradiance for the three-day period (Fig. 3) and the amounts of photons collected. At the end of the experiment, complete conversion was achieved and a yield of $90 \%$ of $\mathbf{3}$ was determined via gas chromatography (GC) analysis (vs. eicosane). During the experimental phase, the three troughs of the PROPHIS plant collected almost 300 mol photons in the important absorption region of 1,4-naphthoquinone between 300-500 nm [9]. Of these, more than $240 \mathrm{~mol}$ were received during the first day alone.

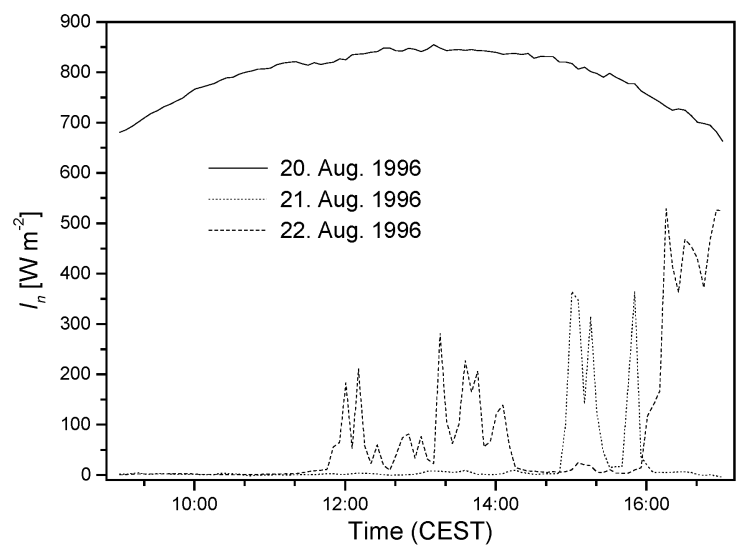

Fig. 3 Direct normal irradiance during the experimental period of the photoacylation. 


\section{Photooxygenation of citronellol}

The photosensitized oxygenation (or Schenck ene reaction) of citronellol was studied as a second example of the solar chemical synthesis concept (Scheme 2) [14]. This reaction is currently performed industrially on a $>100$ t/a scale by Symrise (formerly Dragoco and Haarmann \& Reimer) in Germany using artificial light sources. Subsequent reduction and acid-mediated cyclization of the regioisomer $\mathbf{5 b}$ gives the important fragrance rose oxide. Due to its industrial importance, this photoreaction has become a prototype for solar photochemical comparison studies [15]. For the solar reactions in the PROPHIS loop, the sensitizer rose bengal was selected since it shows a favorable absorption of up to $600 \mathrm{~nm}$ in the solar spectrum (Fig. 2) [3b]. The solvent methanol from the industrial process was replaced by the less hazardous isopropanol.

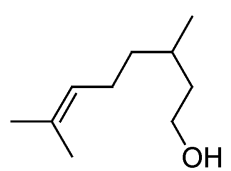

citronellol (4)

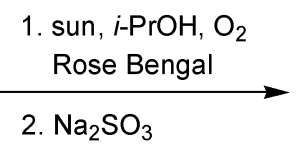

2. $\mathrm{Na}_{2} \mathrm{SO}_{3}$

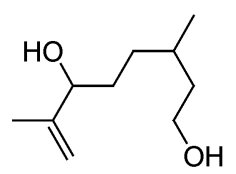

5a $(45 \%)$

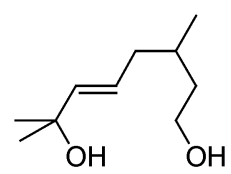

5b $(55 \%)$

Scheme 2 Photooxygenation of citronellol.

The first experiment was performed on 11 August 1997 with only one trough $\left(8 \mathrm{~m}^{2}\right)$, and the reactor was loaded with a solution of 5.81 (31.8 mol) of citronellol (4) and $20 \mathrm{~g}$ of rose bengal in $40 \mathrm{lof}$ isopropanol. Upon illumination, citronellol was rapidly consumed and after ca. $3 \mathrm{~h}$, an almost quantitative conversion of $\mathbf{4}$ was achieved. GC analysis (vs. tetradecane), performed after reduction of the corresponding sample with $\mathrm{Na}_{2} \mathrm{SO}_{3}$, furthermore proved the high purity of the regioisomeric photoproducts, which were formed in a ratio of ca. 45:55 (5a:5b). The latter finding is in good agreement with the reported isolated yield ratio of 35:60 from the laboratory experiments with artificial light [14b]. During the experimental period, the reactor collected $47.1 \mathrm{~mol}$ of photons between 500-600 nm [9]. In the second run on 12 September 2002, all four troughs were used, giving a total aperture of $32 \mathrm{~m}^{2}$. In addition, the experiment was scaled up to 8.01 (43.9 mol) of citronellol and $36 \mathrm{~g}$ of rose bengal in 721 of isopropanol. The weather conditions were again optimal, and consequently total conversion was achieved after less than $2.5 \mathrm{~h}$ (Fig. 4). During this time, the PROPHIS plant received $133.4 \mathrm{~mol}$ of photons in the range of 500-600 nm [9], almost three times as much as during the experiment in 1997. After reduction to the corresponding isomeric diols and acid-catalyzed cyclization, rose oxide was obtained

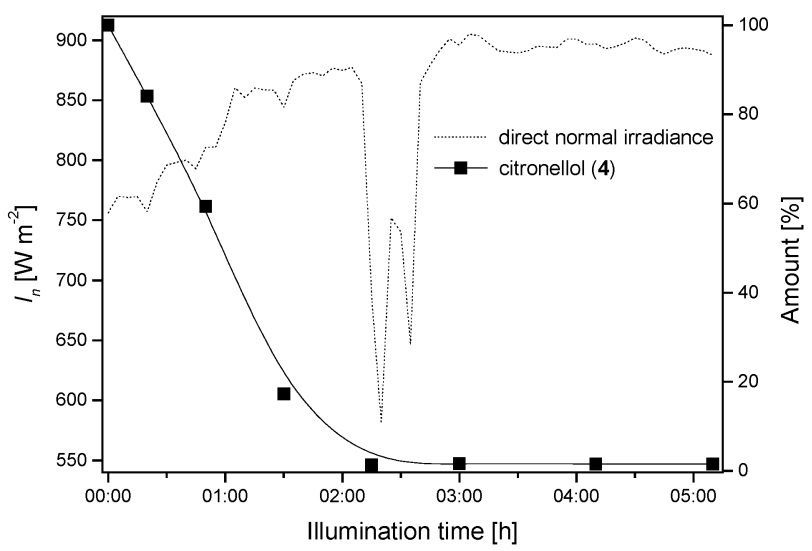

Fig. 4 Direct normal irradiance and conversion vs. illumination time for the photooxygenation of citronellol. 
in excellent quality and in a yield of $>99 \%$ based on the corresponding diol $\mathbf{5 b}$ (55\% based on citronellol).

In 2002, we launched a detailed reactor comparison study (Fig. 5) using 10 vol \% solutions of citronellol in isopropanol and rose bengal $(0.5 \mathrm{~g} / \mathrm{l} i$-PrOH$)$. The PROPHIS loop, a compound parabolic collector (CPC) [16], a flat-bed [17], a horizontal, and a vertical tube reactor were used. The reactors differ in their loaded volumes (20-80 1), apertures, concentration factors, ratios of illuminated vs. nonilluminated area, operation modes (circulating vs. stationary), and oxygen feeding systems. Two series of experiments were performed under perfect (12-13 September) and poor (14-18 October) illumination conditions.

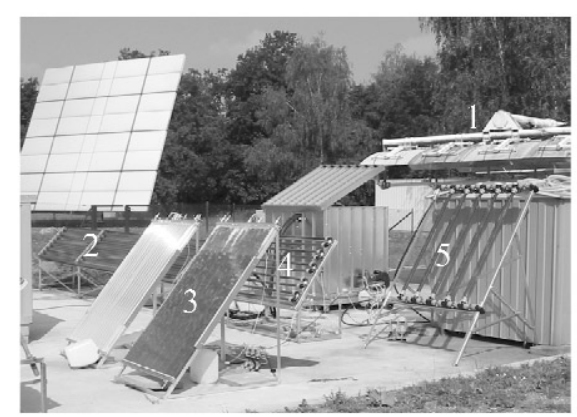

Fig. 5 Reactor comparison study (1: PROPHIS; 2: CPC; 3: flat bed; 4: horizontal tube reactor; 5: vertical tube reactor).

In September, all reactors reached complete conversions after $2.5 \mathrm{~h}$ (PROPHIS) to $15 \mathrm{~h}$ (flat bed). Comparing the conversion based on time and area profiles for all five reactors showed that the CPC and the horizontal tube reactors performed best. This somewhat surprising result can be explained by the different concentration of oxygen inside the reactors as oxygen feeding is optimal for the CPC and horizontal tube reactor. In contrast, the technical set-up used for the more advanced PROPHIS plant allows gas feeding only at the bottom of the first trough. Furthermore, its feeding-nozzle generates relatively large gas bubbles with a small overall surface.

During less favorable weather conditions in October, the CPC and flat-bed reactor gave complete conversions after $30 \mathrm{~h}$. In contrast, the horizontal and vertical tube reactors showed incomplete conversions of $66 \%$ after a slightly longer illumination time of $33 \mathrm{~h}$. The PROPHIS loop did not operate due to its dependence on direct radiation (its troughs are facing the ground in Fig. 5). Judged by conversions based on time and area, the CPC and flat bed performed most efficiently. Possibly, the larger aperture of the flat bed and lack of nonilluminated areas is advantageous under diffuse radiation conditions.

\section{Photooxygenation of 1,5-dihydroxynaphthalene}

An additionally interesting application was the synthesis of the important intermediate juglone (5-hydroxy-1,4-naphthoquinone; 7) from 1,5-dihydroxynaphthalene (Scheme 3) [18]. Most of the corre-

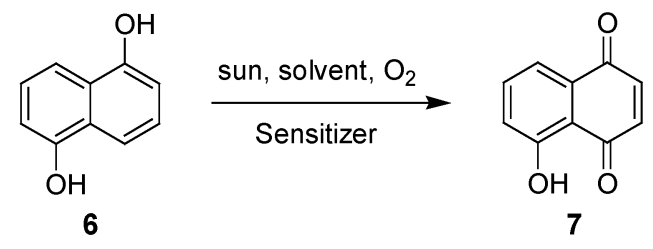

Scheme 3 Photooxygenation of 1,5-dihydroxynaphthalene.

(C) 2007 IUPAC, Pure and Applied Chemistry 79, 1939-1947 
sponding thermal pathways suffer from severe disadvantages concerning yield, selectivity, sustainability, or reproducibility [19]. In contrast, the photosensitized oxygenation of $\mathbf{6}$ with artificial light sources furnishes juglone in yields of 70-88 \%, even on multigram scales [20].

Two solar campaigns were realized in 2003 and 2005. For the solar chemical experiments, we selected a small parabolic trough collector designed for laboratory-scale $(<500 \mathrm{ml})$ applications (Fig. 6a). Its one-axis design allows automatic tracking of the sun for the elevation only, whereas tracking of the azimuth is performed manually every $15 \mathrm{~min}$. The reactor offers a geometric concentration factor of about 15 suns, which is reduced in practice due to optical losses.
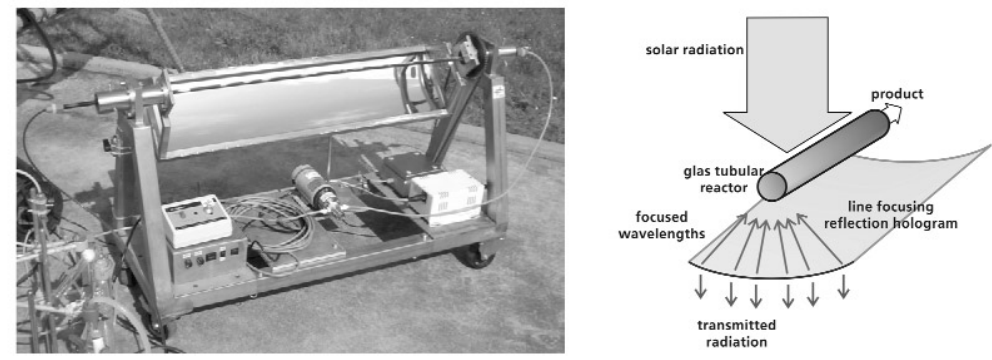

Fig. 6 (a) Parabolic trough reactor; (b) concept of holographic mirrors.

For the first solar campaign in August 2003, the trough was equipped with holographic mirrors (Fig. 6b), which are designed to reduce warm-up effects (and thus the costs for process cooling) caused by infrared radiation. The given holographic concentrators ( 2 elements; $20 \times 100 \mathrm{~cm}$ total) are made of dichromated gelatin (Holotec GmbH/Germany) and show a reflectivity range of $550 \pm 140 \mathrm{~nm}$-optimal for the usage of rose bengal [21]. Two experiments were conducted using rose bengal as sensitizer and isopropanol as solvent [18b]. In contrast, the laboratory procedure commonly uses more hazardous acetonitrile or a mixture of methanol/dichloromethane as solvents [20]. In both cases, the progress of the reaction was followed via GC analysis vs. tetradecane as internal standard. The first test run was performed between 4 and 5 August with $2.0 \mathrm{~g}(12.5 \mathrm{mmol})$ of diol $(6)$ and $0.1 \mathrm{~g}$ of rose bengal in $200 \mathrm{ml}$ of solvent. The starting material was readily consumed, and after less than $8 \mathrm{~h}$, the conversion reached a constant value of $83 \%$. During that period, the reactor collected $7.4 \mathrm{~mol}$ of photons between $500-600 \mathrm{~nm}$ [9]. After work-up, the desired product (7) was obtained in $54 \%$ yield (65\% based on conversion). For the second experiment on 12 August, the amount of diol (6) was reduced to $1.0 \mathrm{~g}$ $(6.2 \mathrm{mmol})$ in order to achieve complete conversion. After less than $3 \mathrm{~h}$ (Fig. 7), GC analysis revealed that most of the starting diol had been consumed. At this stage, the collector has received $2.3 \mathrm{~mol}$ of photons [9]. After a total illumination period of ca. $9.5 \mathrm{~h}$, juglone was isolated in a yield of $79 \%$, which is an improvement on laboratory experiments carried out under identical conditions.

During the second campaign in August and September 2005, the reactor was equipped instead with a highly reflecting eloxated aluminum mirror (as shown in Fig. 6a). In addition, methylene blue was selected as soluble sensitizer since it shows a favorable absorption up to $725 \mathrm{~nm}$ (Fig. 2) [3b]. To simplify the work-up procedure, we furthermore examined solid-supported sensitizers, in particular Sensitox ${ }^{\circledR}$ (rose bengal on Merrifield resin) [22] and methylene blue on ion-exchange resin [23]. Both materials can be easily removed by filtration and are reusable. A total of seven experiments were realized, and two will be highlighted here [18a]. 


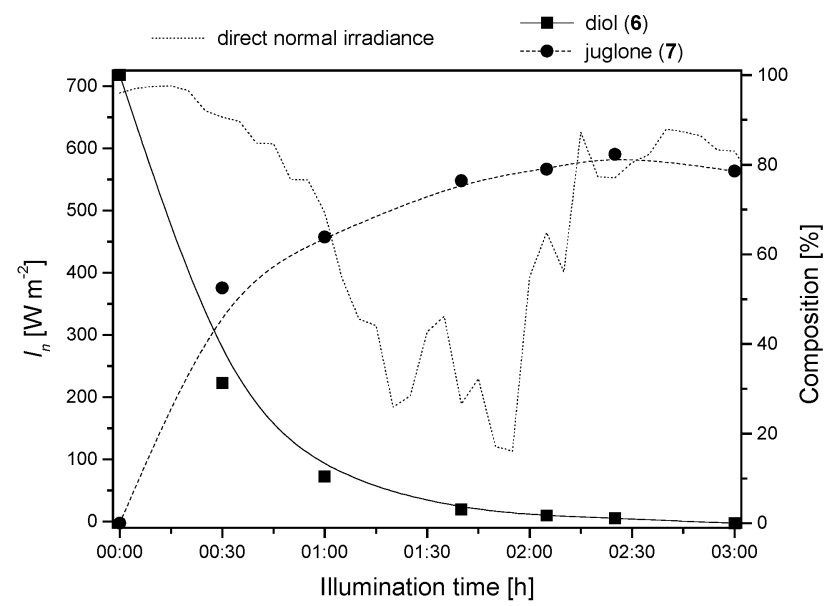

Fig. 7 Direct normal irradiance and product composition vs. illumination time for the rose bengal-mediated photooxygenation of 1,5-dihydroxynaphthalene (August 2003).

The first experiment was conducted on 18 August with $2.0 \mathrm{~g}(12.5 \mathrm{mmol})$ of diol (6) and $0.1 \mathrm{~g}$ of rose bengal in $250 \mathrm{ml}$ of isopropanol under almost perfect illumination conditions. The reaction mixture significantly darkened from bright red to dark brownish-red during the course of the reaction. GC analysis showed that the starting material was rapidly consumed, and after $4 \mathrm{~h}$, the conversion reached an almost constant value of $93 \%$. During the experimental period, the reactor collected 2.0 mol of photons between 500-600 nm [9]. Juglone (7) was obtained in a high yield of 75\% (81\% based on conversion of 6) after work-up. Soluble methylene blue $(0.05 \mathrm{~g})$ was used in the second run, again under perfect insolation conditions. The color of the reaction mixture turned dark green-blue during the experimental period, but this did not affect the progress of the photooxygenation (Fig. 8). At the end of the reaction, the conversion was determined as $83 \%$ and juglone was obtained in a lower yield of $62 \%$ (75\% based on conversion) compared to the rose bengal case. This finding is in line with the lower solar sensitizing efficiency of 0.37 for methylene blue (vs. 0.54 for rose bengal) [3b]. During the illumination, the reactor received $2.1 \mathrm{~mol}$ of photons between $600-700 \mathrm{~nm}$ - the important absorption range of methylene blue [9].

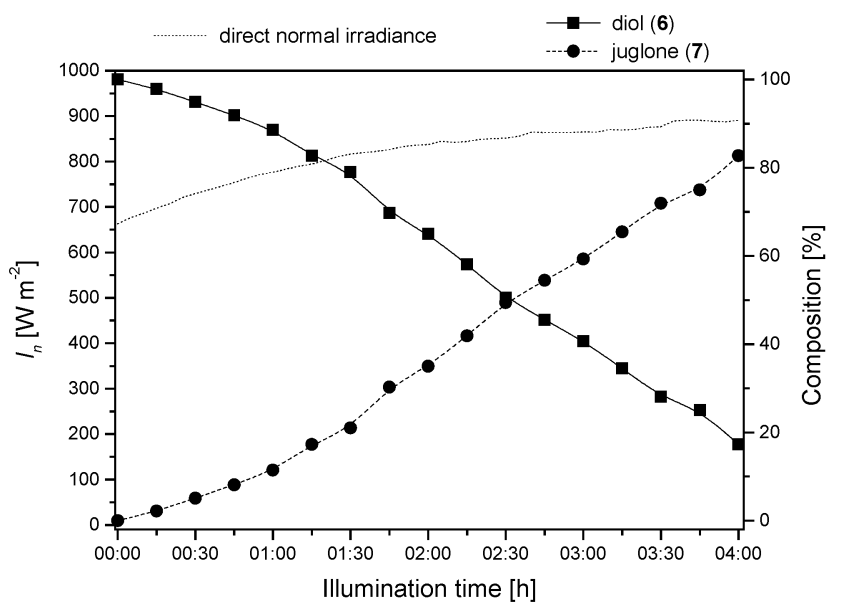

Fig. 8 Direct normal irradiance and product composition vs. illumination time for the methylene blue-mediated photooxygenation of 1,5-dihydroxynaphthalene (August 2005). 
As would be expected from the heterogeneous reaction conditions, the solid-supported sensitizers gave significantly lower yields and conversions after $4 \mathrm{~h}$ of illumination. Methylene blue on ion-exchange resin furthermore showed severe leaching.

Although the photooxygenations of $\mathbf{6}$ required relatively long illumination times in comparison to the large-scale experiments involving citronellol (4), it should be taken into account that solar chemical experiments with nonconcentrated sunlight often require several days or weeks to reach high conversion rates [24]. Furthermore, the oxygen feeding mechanism of the reactor used was not optimal. Oxygen gas was fed in via a simple T-connector which limited its homogeneous distribution within the absorber tube.

\section{CONCLUSION}

The results obtained from the solar photochemical experiments described above clearly show that the solar chemical bulk production of specific fine chemicals can serve as a useful and environmentally friendly alternative to existing technical processes. Cost estimations for specific fine chemicals (e.g., rose oxide [15] or $\varepsilon$-caprolactam [25]) furthermore prove that an industrial solarchemical production can operate economically. Consequently, a realization of Giacomo Ciamician's spectacular vision of the "Photochemistry of the Future" [26] seems within range.

\section{ACKNOWLEDGMENTS}

This research project was financially supported by the Arbeitsgemeinschaft Solar Nordrhein-Westfalen (Themenfeld 3: Solare Chemie und Solare Materialuntersuchungen), the National Institute for Cellular Biotechnology (PRTLI-3), Science Foundation Ireland (06-RF-CHO028 and 07-RF-EEEOBF768), the Environmental Protection Agency (2007-PhD-ET7), and Dublin City University (Research Alliance Fund). The authors would like to thank Prof. Martin Demuth for providing the flat-bed reactor, and Dr. Christian Sattler and Damien McGuirk for technical assistance. JM expresses his deep appreciation to all of the enthusiastic coworkers mentioned in the references.

\section{REFERENCES}

1. (a) P. Tundo, P. Anastas, D. StC. Black, J. Breen, T. Collins, S. Memoli, J. Miyamoto, M. Polyakoff, W. Tumas. Pure Appl. Chem. 72, 1207 (2000); (b) P. T. Anastas, J. C. Wagner. Green Chemistry: Theory and Practice, Oxford University Press, Oxford (1998).

2. (a) A. Albini, M. Fagnoni. Green Chem. 6, 1 (2004); (b) J. Mattay. Chem. Unserer Zeit 36, 98 (2002); (c) A. Albini, M. Fagnoni, M. Mella. Pure Appl. Chem. 72, 1321 (2000); (d) A. G. Griesbeck, W. Kramer, M. Oelgemöller. Green Chem. 1, 205 (1999).

3. (a) B. Pohlmann, H.-D. Scharf, U. Jarolimek, P. Mauermann. Sol. Energy 61, 159 (1997); (b) P. Esser, B. Pohlmann, H.-D. Scharf. Angew. Chem., Int. Ed. 33, 2009 (1994).

4. (a) H. D. Roth. Pure Appl. Chem. 73, 395 (2001); (b) H. D. Roth. Angew. Chem., Int. Ed. 28, 1193 (1989).

5. For overviews on different reactor types, see: (a) S. Malato, J. Blanco, A. Vidal, C. Richter. Appl. Catal., B 37, 1 (2002); (b) K.-H. Funken, J. Ortner. Z. Phys. Chem. 213, 99 (1999).

6. (a) M. Oelgemöller, C. Jung, J. Ortner, M. Mattay, C. Schiel, E. Zimmermann. The Spectrum 18, 28 (2005); (b) M. Oelgemöller, C. Jung, J. Ortner, J. Mattay, C. Schiel, E. Zimmermann. In Proc., 2004 International Solar Energy Conference - Portland, USA, ISEC 2004-65021. ASME, Boulder, CO (2004) (CD-ROM); (c) B. Pohlmann, H.-D. Scharf, U. Jarolimek, P. Mauermann. Sol. Energy 61, 159 (1997); (d) P. Esser, B. Pohlmann, H.-D. Scharf. Angew. Chem., Int. Ed. 33, 2009 (1994).

7. K.-H. Funken, M. Becker. Renew. Energy 24, 469 (2001). 
8. C. Jung, K.-H. Funken, J. Ortner. Photochem. Photobiol. Sci. 3, 409 (2005).

9. Calculated using SEDES for Windows: T. Walsch, K.-J. Riffelmann. SEDES for Windows, Version 2.5, DLR, Köln (1997).

10. M. Oelgemöller, J. Mattay. In CRC Handbook of Organic Photochemistry and Photobiology, $2^{\text {nd }}$ ed., W. M. Horspool, F. Lenci (Eds.), Chap. 88, pp. 1-45, CRC Press, Boca Raton, FL (2004) and refs. therein.

11. (a) H. Klinger, O. Standke. Ber. Dtsch. Chem. Ges. 24, 1340 (1891); (b) H. Klinger, W. Kolvenbach. Ber. Dtsch. Chem. Ges. 31, 1214 (1898).

12. (a) P. A. Waske, J. Mattay, M. Oelgemöller. Tetrahedron Lett. 47, 1329 (2006); (b) M. Oelgemöller, C. Schiel, J. Mattay, R. Fröhlich. Eur. J. Org. Chem. 2465 (2002); (c) C. Schiel, M. Oelgemöller, J. Mattay. Synthesis 1275 (2001); (d) C. Schiel, M. Oelgemöller, J. Mattay. J. Inf. Rec. 24, 257 (1998).

13. (a) C. Schiel, M. Oelgemöller, J. Ortner, J. Mattay. Green Chem. 3, 224 (2001); (b) M. Oelgemöller, C. Schiel, J. Ortner, J. Mattay. In AG Solar Nordrhein-Westfalen - Solare Chemie und Solare Materialforschung, Chap. 2.2, AG-Solar NRW, Jülich (2002) (CD-ROM).

14. (a) W. Rojahn, H.-U. Warnecke. DRAGOCO-Report 27, 159 (1980); (b) G. Ohloff, E. Klein, G. O. Schenck. Angew. Chem. 73, 578 (1961).

15. N. Monnerie, J. Ortner. J. Sol. Energy Eng. 123, 171 (2001).

16. (a) J. I. Ajona, A. Vidal. Sol. Energy 68, 109 (2000); (b) J. Blanco, S. Malato, P. Fernández, A. Vidal, A. Morales, P. Trincado, J. C. Oliveira, C. Minero, M. Musci, C. Casalle, M. Brunotte, S. Tratzky, N. Dischinger, K.-H. Funken, C. Sattler, M. Vincent, M. Collares-Pereira, J. F. Mendes, C. M. Rangel. Sol. Energy 67, 317 (1999).

17. (a) C. Heinemann, X. Xing, K.-D. Warzecha, P. Ritterskamp, H. Görner, M. Demuth. Pure Appl. Chem. 70, 2167 (1998); (b) M. Demuth, A. Ritter. WO patent 99/54032 (1999).

18. (a) M. Oelgemöller, N. Healy, L. de Oliveria, C. Jung, M. Mattay. Green Chem. 8, 831 (2006); (b) M. Oelgemöller, C. Jung, J. Ortner, M. Mattay, E. Zimmermann. Green Chem. 7, 35 (2005).

19. For overviews on thermal preparations of juglone, see: (a) D. J. Crouse, M. M. Wheeler, M. Goemann, P. S. Tobin, S. K. Basu, D. M. S. Wheeler. J. Org. Chem. 46, 1814 (1981); (b) C. Grundmann. Synthesis 644 (1977).

20. (a) O. Suchard, R. Kane, B. J. Roe, E. Zimmermann, C. Jung, P. A. Waske, J. Mattay, M. Oelgemöller. Tetrahedron 62, 1467 (2006); (b) D. Murtinho, M. Pineiro, M. M. Pereira, A. M. d'A. Rocha Gonsalves, L. G. Arnaut, M. da Graça Miguel, H. D. Burrows. J. Chem. Soc., Perkin Trans. 22441 (2000); (c) S. Croux, M.-T. Maurette, M. Hocquaux, A. Ananides, A. M. Braun, E. Oliveros. New J. Chem. 14, 161 (1990); (d) G. Wurm, U. Geres. Arch. Pharm. (Weinheim) 318, 931 (1985); (e) H.-J. Durchstein, G. Wurm. Arch. Pharm. (Weinheim) 317, 809 (1984); (f) J. Griffiths, K.-Y. Chu, C. Hawkins. J. Chem. Soc., Chem. Comm. 676 (1976).

21. J. Ortner, D. Faust, K.-H. Funken, T. Lindner, J. Schulat, C. G. Stojanoff, P. J. Fröning. Phys. IV (France) 9, Pr3-379 (1999).

22. (a) B. Paczkowska, J. Paczkowski, D. C. Neckers. Macromolecules 19, 863 (1986); (b) A. P. Schapp, A. L. Thayer, E. C. Blossey, D. C. Neckers. J. Am. Chem. Soc. 97, 3741 (1975); (c) E. C. Blossey, D. C. Neckers, A. L. Thayer, A. P. Schapp. J. Am. Chem. Soc. 95, 5820 (1973).

23. J. R. Williams, G. Orton, L. R. Unger. Tetrahedron Lett. 14, 4603 (1973).

24. For some selected examples, see: (a) A. Itoh, S. Hashimoto, K. Kuwabara, T. Kodama, Y. Masaki. Green Chem. 7, 830 (2005); (b) R. A. Doohan, N. W. A. Geragthy. Green Chem. 7, 91 (2005); (c) J.-T. Li, J.-H. Yang, J.-F. Han, T.-S. Li. Green Chem. 5, 433 (2003); (d) T. Rüther, A. M. Bond, W. R. Jackson. Green Chem. 5, 364 (2003).

25. (a) K.-H. Funken, F.-J. Müller, J. Ortner, K.-J. Riffelmann, C. Sattler. Energy 24, 681 (1999); (b) C. Sattler, F.-J. Müller, K.-J. Riffelmann, J. Ortner, K.-H. Funken. J. Phys. IV (France) 9, Pr3-723 (1999).

26. G. Ciamician. Science 36, 385 (1912). 